\title{
ТРАНСФОРМАЦИЯ ПОНЯТИЯ «ЭКОЛОГИЧНОСТЬ» В ИНДУСТРИИ МОдЫ
}

\author{
B. С. Сапожникова \\ Московский гуманитарный университет
}

\begin{abstract}
Аннотация: В статье показано, что в современном обществе смещается понимание «экологичности» от природного к технологическому. И в таком виде оно оказывает существенное влияние на феномен моды.

Текст доклада автора на Общероссийской (национальной) научной конференции «Моисеевские чтения. Культура и гуманитарные проблемы современной цивилизации», которая состоялась 4-5 марта 2020 г. в Московском гуманитарном университете.
\end{abstract}

Ключевые слова: высокие технологии; экологичность; утилизация; производство

\section{TRANSFORMATION OF THE NOTION “ECOLOGICAL SAFETY” IN THE FASHION SPHERE}

\author{
V.S. Sapozhnikova \\ Moscow University for the Humanities
}

Abstract: The article shows that in modern society the notion "ecological safety" shifts from natural to technological orientation. In this new form it has a significant impact on the fashion phenomenon.

The text of the author's speech at the All-Russian (National) Scientific Conference "Moiseev's Readings. The Culture and Humanitarian Issues of Modern Civilisation", which was held at Moscow University for the Humanities on 4-5 March, 2020.

Keywords: high technology; ecological safety; disposal; production

Индустрия моды является одной из сфер экономики, наносящих максимальный урон окружающей среде. Если еще несколько десятилетий назад под экологичным материалом понимался материал природный, натуральный, то сегодня такие ткани, как, например, хлопок или шерсть стремятся быть исключенными из этой категории. И наоборот: материалы полностью искусственного происхождения склонны называться экологичными. Их всячески популяризируют и активно внедряют в массовое производство. Понятие экологичности хлопка пересматривается в виду чрезвычайно большого потребления воды этой культурой. Для производства хлопкового волокна требуется тысячи литров воды. По данным Всемирного фонда дикой природы, на производство конечного продукта из хлопка - такого, как джинсы или футболка, с момента высадки растения и до отправки в магазин затрачивается более 9000 (девяти тысяч) литров воды на 1 изделие. В сегодняшних условиях борьбы за водные ресурсы хлопок рассматривают как находящийся в категории неэкологичных образцов, способствующих обезвоживанию планеты.

Похожую ситуацию можно наблюдать с натуральной овечьей шерстью. Считающаяся до недавнего времени практически незаменимым, теплым, абсолютно 
экологичным материалом, шерсть сегодня критикуется за свою «неэкологичность». Овцы как основной источник шерсти способствуют опустыниванию почвы. Пастбища тяжело и долго восстанавливаются после выпаса этих животных. Учитывая постоянно растущее потребление в шерсти, прямо пропорционально возрастает и урон, наносимый природе.

Вторая сторона экологичности продукции связана с их утилизацией. На замену натуральным тканям предлагаются новые технологичные, искусственные материи. Однако вопрос утилизации практически опускается, хотя он в рамках охраны и заботе о природе имеет первостепенное значение. Если хлопок и шерсть, как и любое другое натуральное волокно, легко утилизируется и не загрязняет окружающую среду (является органикой), то синтетические материалы, как правило, нуждаются в дополнительных затратах на переработку или утилизацию. Далеко не каждый современный искусственный материал возможно заново переработать или уничтожить без ущерба для окружающей среды.

Бесспорно, на замену одних натуральных материалов (того же хлопка) ученые готовятся предложить их природные аналоги. Например, ткани из ферментированного чая. Разработана технология Kombucha. Благодаря ей специалисты производят одежду из обычного чая. Сегодня она пользуется незначительной популярностью среди дизайнеров одежды, и в разряд массовых технологий не перешла. В качестве альтернативы предлагаются к массовому производству и другие ткани растительного производства (из конопли, крапивы и т.д.) и даже биологически выращенные в лабораториях, но эти проекты развиваются недостаточно быстро, в отличии от разработок технологических.

В современном информационном обществе природное происхождение уходит из понятия «экологичности». В свою очередь, материалы искусственного производства осваивают сферу современной экологичности весьма активно. Этому способствует целый ряд факторов. Основным является положительно окрашенный контекст и популярность самого термина, ставшего модным лозунгом для политиков, чиновников, активистов. За экологичностью как целым направлением стоят и крупные организации (Green Peace, Green Cross, Фонд дикой природы, международный союз охраны природы и природных ресурсов и т.д.), ученые, исследовательские институты и отдельные медийные личности, начиная от знаменитых моделей, актеров, политиков и заканчивая не получившими полноценного образования подростками, такими как известная сегодня Гретта Тунберг.

Под лозунгом экологичности можно с высокой долей вероятности провести законопроект, получить ссуду, закрыть одни предприятия и открыть другие, запретить курение табака и легализовать наркотики и т. д. Экологичностью в современном обществе можно манипулировать, реализуя необходимые задачи.

В эпоху развивающегося информационного общества, отказываясь от натуральной природы своего происхождения в пользу природы технологической, данная дефиниция должна превознести и сделать востребованными плоды высоких технологий, рукотворных достижений и новых интересов. 
Сапожникова Виктория Станиславовна - аспирант кафедры философии, культурологии и политологии Московского гуманитарного университета. Адрес: 111395, Россия, г. Москва, ул. Юности, д. 5. Эл. адрес: sivika@yandex.ru

Sapozhnikova Victoria Stanislavovna, Postgraduate Student, Department of Philosophy, Cultural Studies and Political Science, Moscow University for the Humanities. Postal address: 5, Yunosti St., Moscow, Russian Federation, 111395. E-mail: sivika@yandex.ru труды Московского гуманитарного университета. 2020. №3. C. 4-6. DOI: https://www.doi. org/10.17805/trudy.2020.3.1 